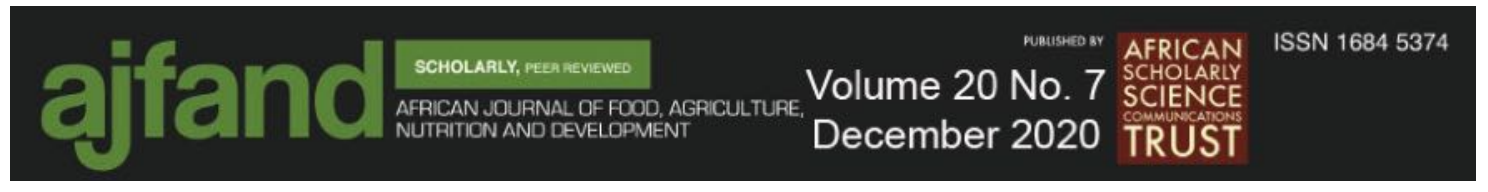

Afr. J. Food Agric. Nutr. Dev. 2020; 20(7): 16922-16940 $\quad$ https://doi.org/10.18697/ajfand.95.18635

\title{
EFFECTS OF EXTRACTABLE PROTEIN HYDROLYSATES, LIPIDS, AND POLYPHENOLIC COMPOUNDS FROM PEARL MILLET (PENNISETUM GLAUCUM (L.) R. BR.) WHOLE GRAIN FLOURS ON STARCH DIGESTIBILITY
}

\section{Terbag $\mathbf{L}^{1,2}$, Souilah $\mathbf{R}^{1,2 *}$, Belhadi $\mathbf{B}^{1,3}$, Lemgharbi $\mathbf{M}^{1}$, Djabali $D^{1}$ and B Nadjemi ${ }^{1}$}

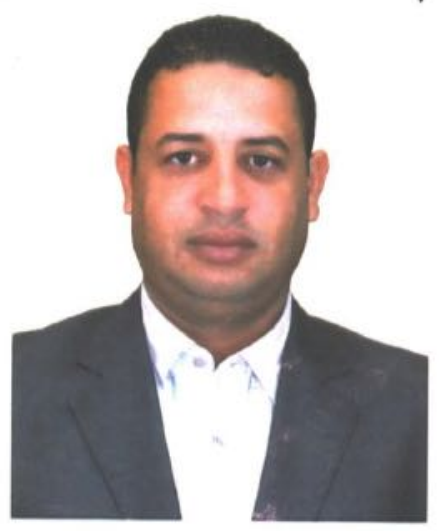

Ladjel Terbag

*Corresponding author email: souilah2004@yahoo.fr

${ }^{1}$ Laboratoire d'Etudes et Développement des Techniques d'Epuration et de Traitement des Eaux et Gestion Environnementale, E.N.S, Cheikh Mohamed El Bachir El Ibrahimi, Kouba, Algiers, Algeria

${ }^{2}$ Dpt physique, E.N.S, Taleb Abderrahmane, Laghouat, Algeria

${ }^{3}$ Dpt sciences et techniques, Faculté de technologie, Université Amar Télidji Laghouat, Alg 


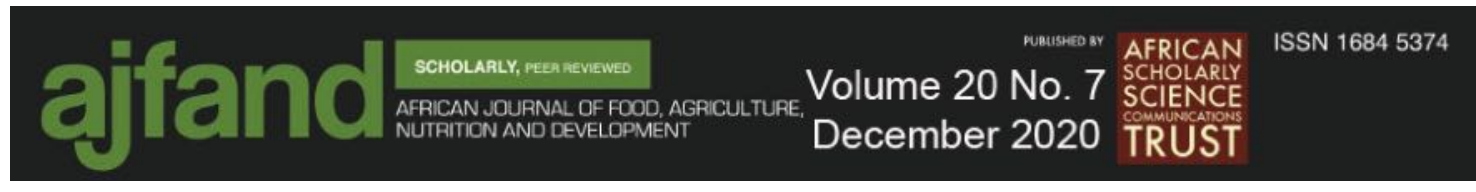

\begin{abstract}
Pearl millet and other minor cereal production is marginalized in the Sahara of Algeria (Tidikelt and Hoggar regions). Their productions in these areas depend on traditional harvesting and processing. Pearl millet seeds are used as animal feed and rarely for human consumption. This work was to assess the starch digestion of pearl millet cultivated in the arid areas of Algeria. The seeds from this cereal could provide broad potential benefits to human health. However, their digestion properties have not been reported. Therefore, in this study, the in-vitro starch digestibility of pearl millet flour and the effect of processing on the expected glycemic index (eGI) were investigated. Grains from six pearl millet samples were chosen from two regions: Tidikelt and Hoggar. Five flours were prepared by dry milling (MF) and different treatments after dry milling such as extraction of phenolic compounds (MF-PP), lipid extraction (MF-L), protein hydrolysate extraction (MF-P) or lipid plus protein hydrolysate extraction (MF-L-P). The flours were then subjected to digestion, and the effects of grain treatments on the in vitro starch digestion were investigated. For all pearl millet samples, the kinetics of in vitro starch digestion displayed first-order model as substrates were digested to different extents; $\mathrm{k}$ (kinetic constant), $\mathrm{C}_{\infty}$ (percentage of starch hydrolyzed at infinite time), HI (hydrolysis index) and eGI (expected glycemic index) of the samples were also calculated. Significant increases in $\mathrm{C}_{\infty}$, $\mathrm{HI}$ and eGI $(\mathrm{P}<0.05)$ of the samples were observed after extraction of proteins or proteins plus lipids from flour. Four flours obtained after lipid extraction and five flours from extraction of phenolic compounds had low glycemic index $(<55)$, with values ranging between 31.36 and 44.97. In contrast, flours obtained from protein hydrolysate extraction or lipids plus protein hydrolysates had the highest glycemic index ( $>69)$, with values ranging between 77.50 and 121.44. This study confirmed that some of the processed pearl millet seed flours have acceptable nutritional values suitable for human health and nutrition due to the low glycemic index values.
\end{abstract}

Key words: Pearl millet, Grain processing, Starch digestion, First-order model, Glycemic index 


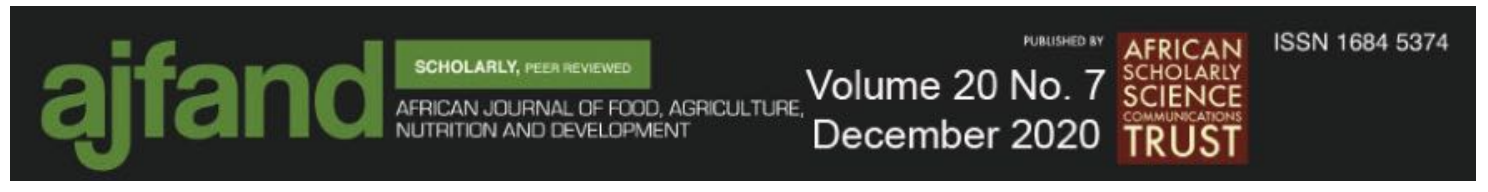

\section{INTRODUCTION}

Millets are important crops in semi-arid and tropical regions of the world [1]. The most important species are pearl millet, finger millet, proso millet, and foxtail millet. Pearl millet accounts for almost half of global millet production in the world [2]. Millets are the most drought-tolerant cereal grain crops and require little input during growth, but as with other crops, yield better with good husbandry [1, 3, 4]. In Algeria, pearl millet [Pennisetum glaucum (L.) R. Br.] is an important crop. These millet grains are grown in Tidikelt and Hoggar regions, and their characteristics are defined and reported by Lemgharbi et al. [5, 6] who indicated that pearl millet was produced by small-scale farmers for household consumption. Pearl millet seeds are used as animal feed and rarely for human consumption in Algeria.

Millet grains have good nutritional value, in terms of proteins and amino acids, carbohydrates, fats, vitamins, minerals, and energy values. They are comparable to the popular cereals like rice, wheat, and barely $[1,3]$. Millets are accepted as functional and nutraceutical food because they provide dietary fibre, protein, energy, minerals, vitamins, and antioxidants required for human health $[7,8]$.

Over several decades, the trend has been towards consumption of highly processed foods, which is linked to occurrence of a variety of chronic illnesses, for instance type 2 diabetes, hyperlipidemia, obesity, and cardiovascular problems $[9,10]$. The main reason behind all this has been agreed upon to be due to overconsumption of digestible carbohydrates (starches), which are quickly absorbed from the gastrointestinal tract (GIT), and thus resulting in a "spike" of normal blood glucose levels [9]. Formulating foods which may regulate the levels of starch digestion, so as to prevent the high spike of blood glucose rates is consequently desirable.

The aim of this study was to evaluate the digestibility of starch in the Algerian arid areas pearl millet grain cultivars, by evaluating the effects of non-starch compounds (proteins, lipids and phenolic compounds) on the parameters of the in-vitro starch digestion kinetics and the expected glycemic index (eGI).

\section{MATERIALS AND METHODS}

\section{Materials}

Grains from five landraces and one introduced pearl millet (P. glaucum $(L) R$. Br) were sampled from the arid Sahara areas of south Algeria: Tidikelt and Hoggar. Table 1 lists sample codes, locality, region and status.

\section{Methods}

Five flours were prepared from each sample. The first millet flour (MF) was prepared by dry milling. Other flours were prepared by dry milling combined with different treatments such as extraction of phenolic compounds (MF-PP), lipid extraction (MF-L), protein hydrolysate extraction (MF-P) or lipid plus protein hydrolysate extraction (MFP-L). The processed flours were subsequently subjected to digestion assays. All the reagents used for analysis were of analytical grade. 


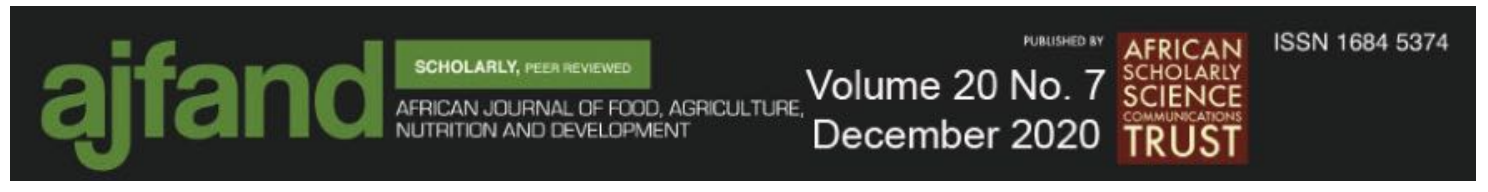

Dry milling: The millet grains were ground to flour in IKA Labotechik A10 sample mill. The obtained flours were manually sieved over a $500 \mu \mathrm{m}$ sieve.

Lipid Extraction: Flour samples ( $5 \mathrm{~g}$ ) were treated with n-hexane using the Soxhlet apparatus by refluxing for $5 \mathrm{~h}$. The defatted flour (MF-L) was dried directly in drying oven at $40{ }^{\circ} \mathrm{C}$ overnight.

Protein Hydrolysates Extraction: Millet flour (MF) was treated with protease according to the method reported by Goni et al. [12] with modifications. One hundred and sixty milliliters $(160 \mathrm{~mL})$ of $\mathrm{HCl}-\mathrm{KCl}$ buffer solution at $\mathrm{pH} 4.0$ was added to $20 \mathrm{~g}$ of flour (MF) and the contained immersed in a water bath. To start protease treatments, $40 \mathrm{~mL}$ of pepsin $(1 \mathrm{mg} / \mathrm{mL})$ from porcine gastric mucosa $(800-2,500 \mathrm{U} / \mathrm{mg}$ protein, Sigma-Aldrich (P7000)) was added. The prepared mixture was incubated at $40{ }^{\circ} \mathrm{C}$ for $1 \mathrm{~h}$ with constant shaking and then the suspension centrifuged (10 min, $28630 \mathrm{rpm})$. The supernatant was removed using a spatula and the residue (free of extractable protein hydrolysate) (MF-P) was dried directly in a drying oven at $40{ }^{\circ} \mathrm{C}$ overnight.

Protein and Lipid Extraction: To prepare the flour (MF-L-P), sample flour obtained after lipid extraction was treated with pepsin and the protein hydrolysate removed as described above.

Extraction of Phenolic Compounds: According to the method reported by Khadambi[13] with modification, the extracts of phenolic compounds were prepared by suspending a sample $(3 \mathrm{~g})$ of $\mathrm{MF}$ in $150 \mathrm{~mL}$ in aqueous acetone $(75 \% \mathrm{v} / \mathrm{v})$. The mixture was incubated at room temperature for $2 \mathrm{~h}$ with constant shaking. The suspension was centrifuged ( $5 \mathrm{~min}, 28630 \mathrm{rpm}$ ), the supernatant removed and the residue obtained (MFPP) was dried directly in an oven at $40^{\circ} \mathrm{C}$ overnight.

\section{Sample Characterization}

The moisture content of all the flours was determined according to AACC methods 4415A. The crude protein content was determined according to micro-Kjeldahl method using nitrogen conversion factor of 5.83, an adaptation of the AACC 46-13A [14]. Total starch (TS) was determined by the enzymatic method [12]. Fat content was determined using the Soxhlet apparatus (n-hexane, $5 \mathrm{~h}$ ) method [15].

\section{In vitro Starch Digestion and Modelling of Starch Digestograms}

The invitro starch digestion was determined according to method of Goni et al. [12] with modifications and a first-order exponential model in kinetics study was used to estimate starch hydrolysis or glycemic indices as previously described $[6,12,16]$.

\section{Statistical Analysis}

All the parameters of sample characterization were measured in three replicates, and expressed as Mean \pm SD. Data were analyzed by one-way analysis of variance (ANOVA) and mean differences were assessed by Fisher's least significant difference test at the level of $p<0.05$ with the SPSS software, V.17. The data analyses were performed with the Sigma Plot V.10.0 (Systat software Inc, Chicago, Illinois, USA) for windows. 


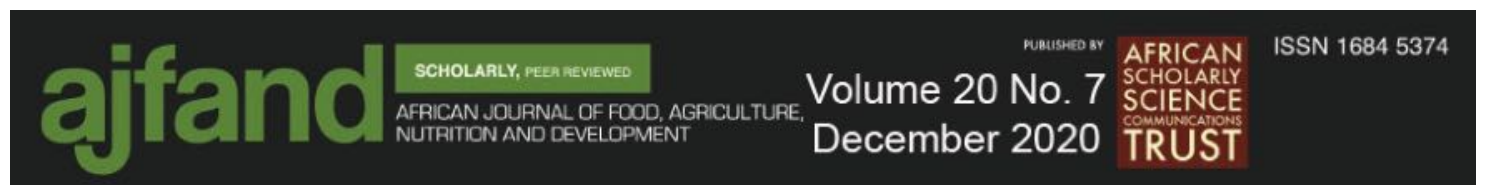

\section{RESULTS AND DISCUSSION}

\section{Sample Characterization}

The pearl millet samples, selected for the study, differed in phenotypic characters, which is indicative of morphologic variation and biodiversity of millet cultivated in Tidikelt and Hoggar regions [6].

As shown in Table 2, the lipids content of pearl millet flours (MF) ranged from 8.27 to $11.18 \%$ with a mean value of $9.43 \%$. Values obtained were higher than reported range of 4.1-6.1\% for the Semi-Arid Tropics ICRISAT [16], as well as 1.5-6.8\% [4] and 1.54.8\% [18]. Moreover, the values obtained were higher than other cereals such as rice $(2.7 \%)$, wheat (2\%), maize (4.6\%) and sorghum (3.1\%) [18]. The percentage of extracted lipids after treatments ranged from 21.70 to $54.38 \%$. This indicated that a high percentage of lipids remained in processed millet grains (MF-P-L).

The protein content of pearl millet flour (MF) ranged from $11.41 \%$ to $16.89 \%$ with a mean value of $14.31 \%$. Values obtained are higher than reported mean value of $10.6 \%$ [17], 11.21\% reported for 10 Sudanese pearl millet varieties [19], and $11.8 \%$ reported [18], but are near the mean value of $14.5 \%$ reported by Taylor [3]. Moreover, the values obtained are higher than other cereals such as brown rice $(7.9 \%)$, wheat $(11.6 \%)$, maize $(9.2 \%)$ and sorghum $(10.4 \%)$ [18]. The percent of extracted proteins after the treatments ranged from 09.77 to $38.54 \%$. The results indicate that a high percentage of protein remained in processed millet samples (MF-P-L). The Algerian pearl millet landraces, as shown, represent a satisfactory source of proteins and lipids for human nutrition.

\section{In vitro Kinetics of Starch Digestion and Modeling}

The starch digestion curves for all pearl millet flours in the present study are shown in Figures 1 to 6 . 

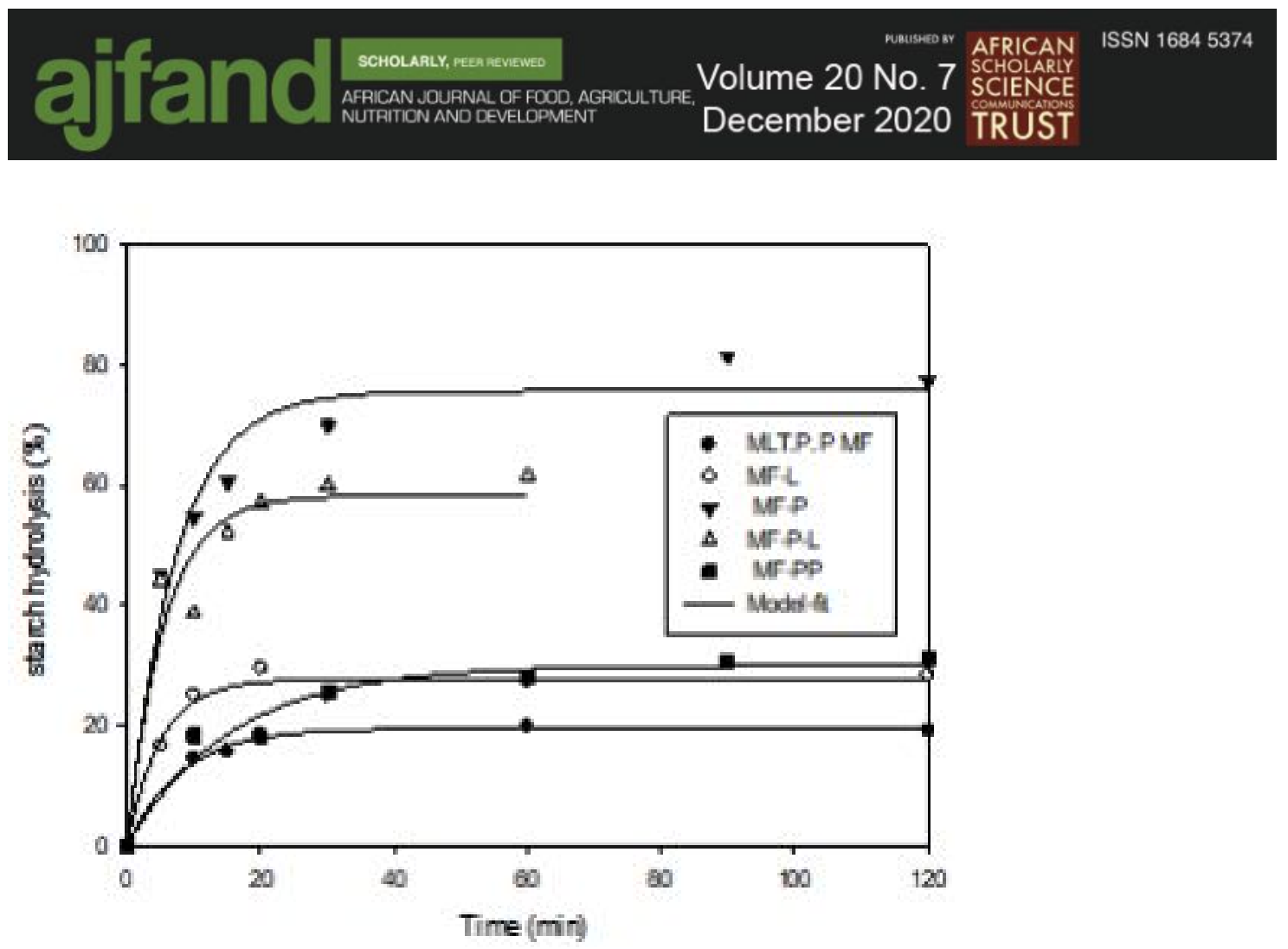

Figure 1: Starch digestibility curves for unprocessed and processed flours from pearl millet sample: MLT.P.P.

$\mathrm{MF}=$ Whole grain flour, MF-L = Flour after extraction of lipids, MF-P = Flour after extraction proteins hydrolysable, MF-P-L $=$ Flour after extraction of lipids and hydrolysable proteins and MF-PP = Flour after extraction of phenolic compounds

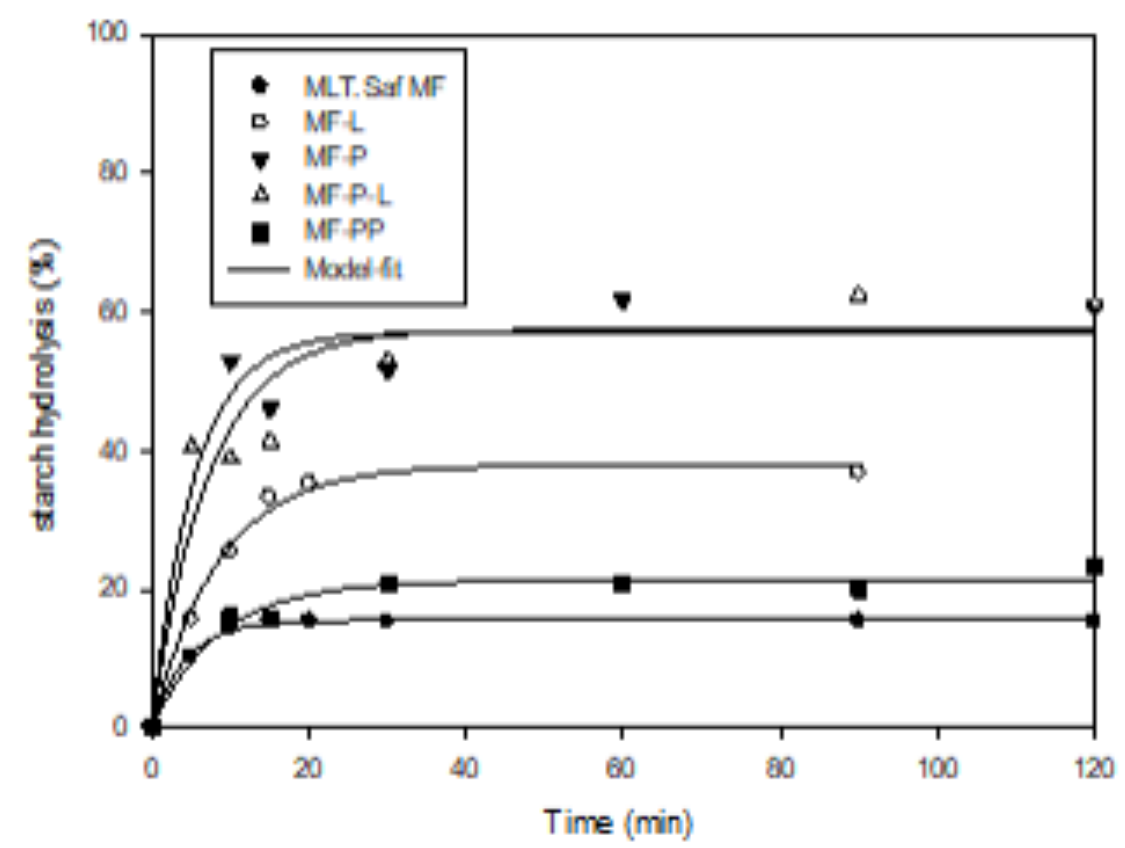

Figure 2: Starch digestibility curves for unprocessed and processed flours from pearl millet sample: MLT.Saf 

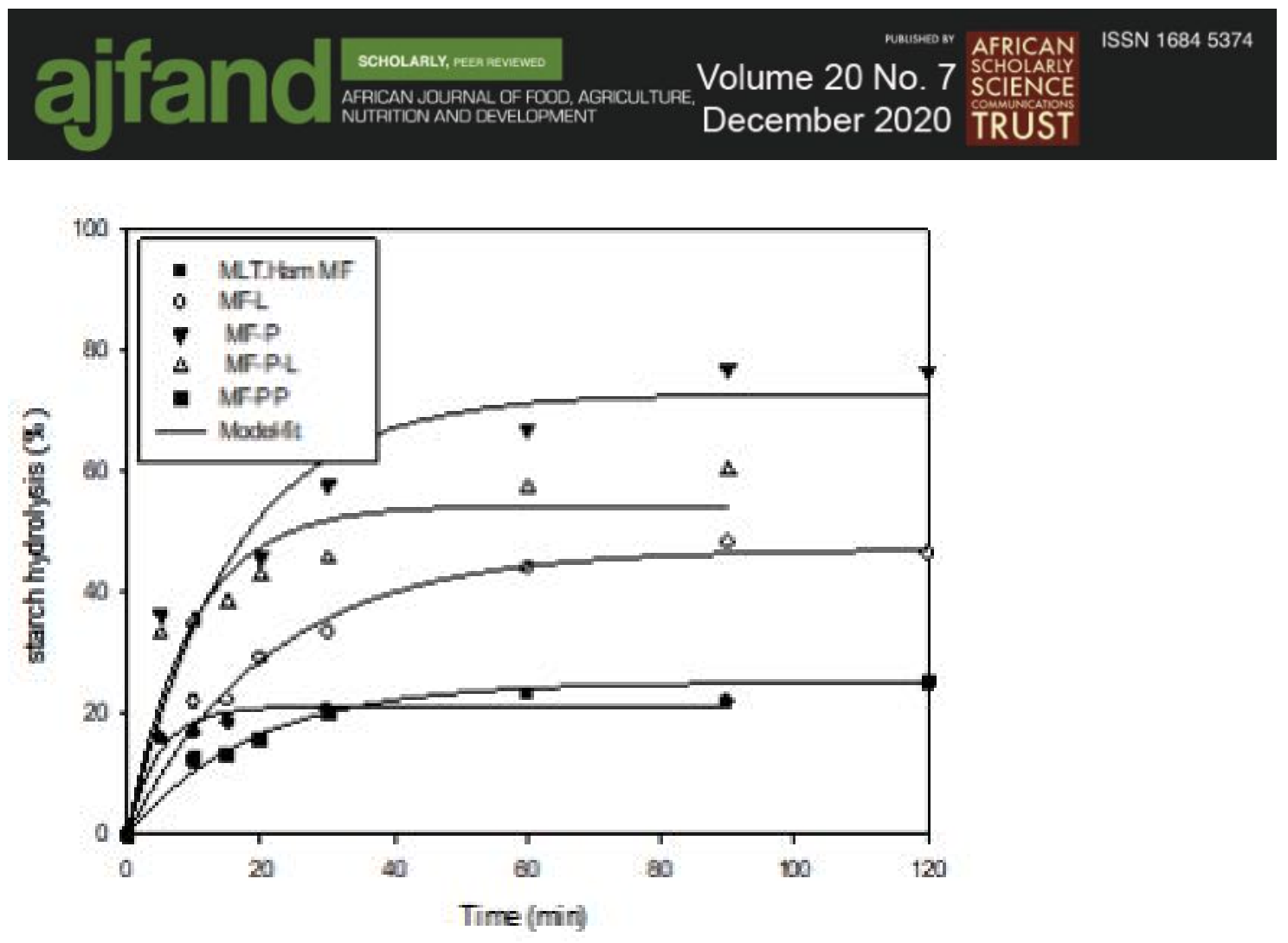

Figure 3: Starch digestibility curves for unprocessed and processed flours from pearl millet sample: MLT.Ham

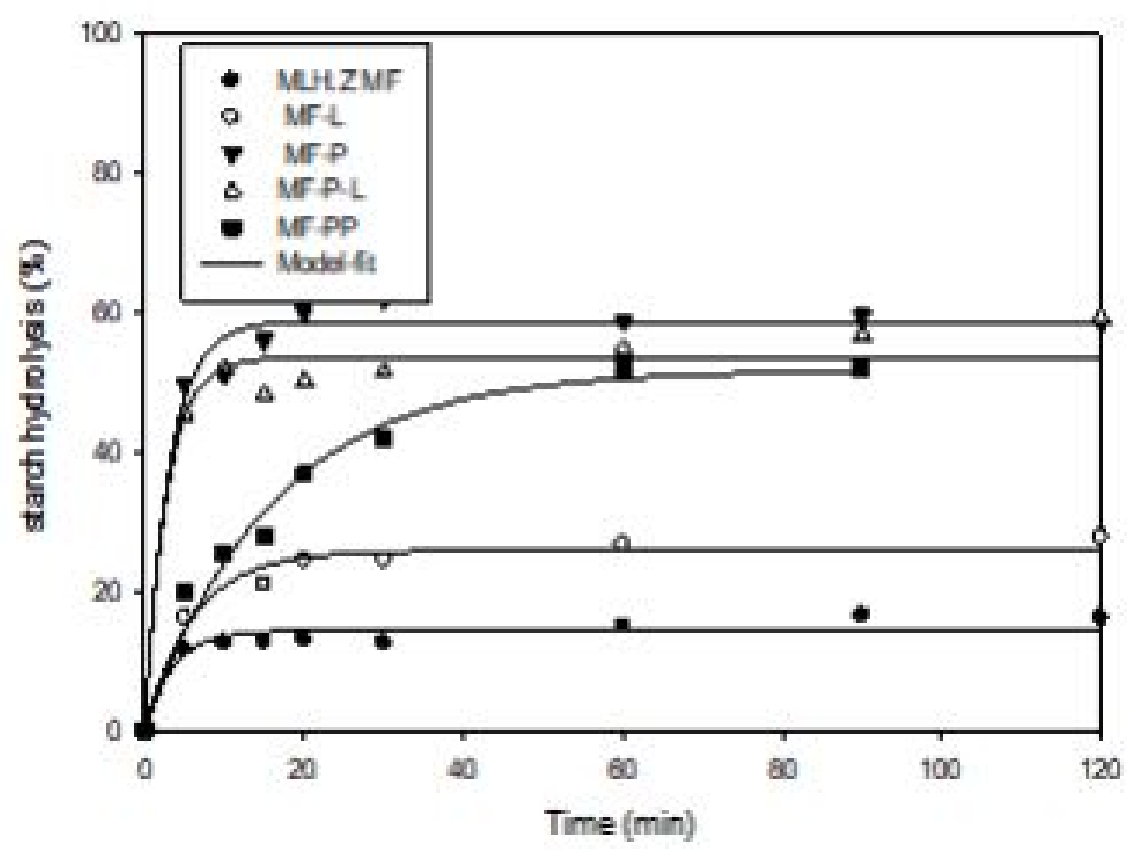

Figure 4: Starch digestibility curves for unprocessed and processed flours from pearl millet sample: MLH.Z. 

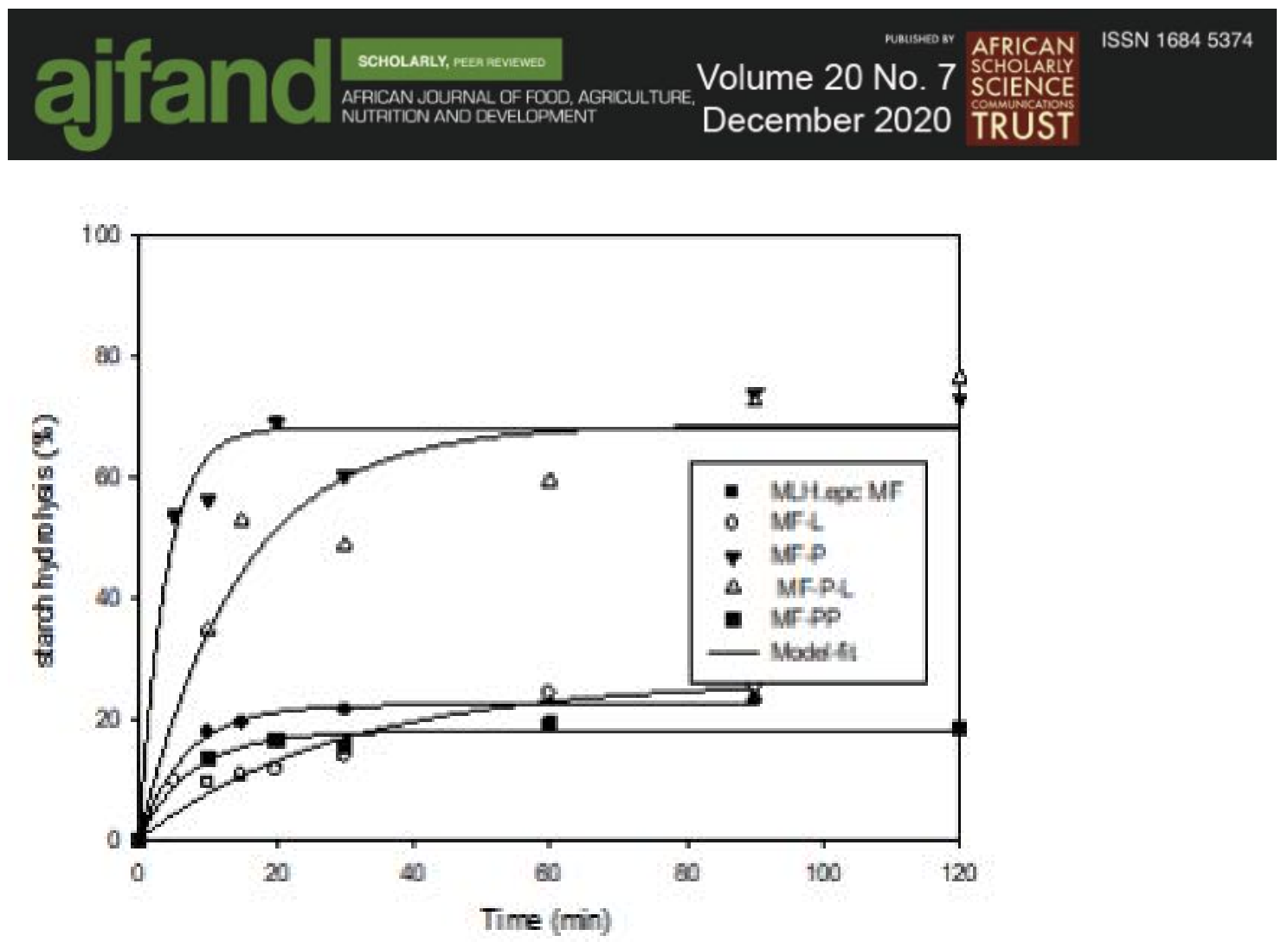

Figure 5: Starch digestibility curves for unprocessed and processed flours from pearl millet sample: MLH.epc.

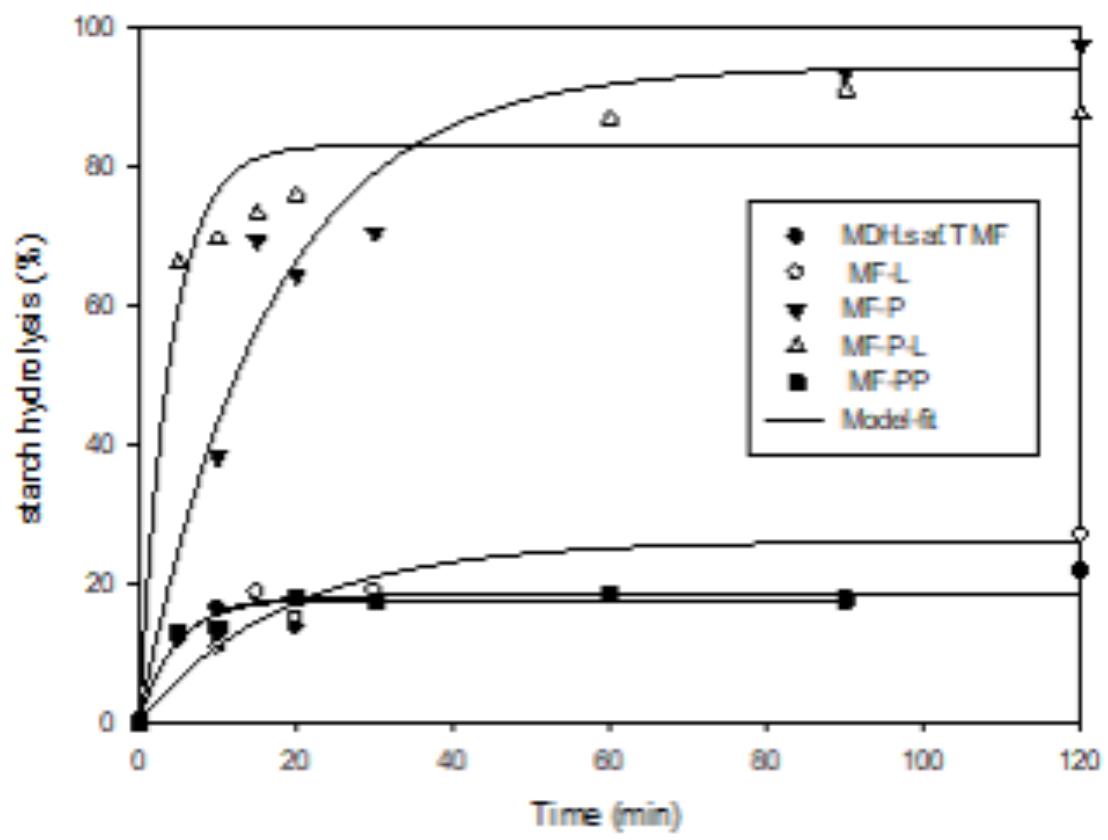

Figure 6: Starch digestibility curves for unprocessed and processed flours from pearl millet sample: MDH.saf.T.

The digestibility curves showed that the pearl millet flours from Algerian landraces were hydrolyzed by amylases in the chosen reaction conditions. The estimated parameters $(\mathrm{k}$, $\left.\mathrm{C}_{\infty}, \mathrm{HI}, \mathrm{eGI}\right)$, by first-model, in starch hydrolysis were obtained by the fit to experimental data, where $\mathrm{k}$ was the rate constant $\left(\mathrm{min}^{-1}\right), \mathrm{C}_{\infty}$ was the percentage of starch hydrolyzed at infinite time, recorded in $120 \mathrm{~min}$, HI the hydrolysis index and eGI the expected 
glycemic index. Overall, the computed digestibility curves provided a very good fit to all experimental data, with $\mathrm{R}^{2}>0.9$ and standard error of estimate (SEE) $<6 \%$ for most samples. The first-order kinetic model was suitable, including the estimated values $\mathrm{k}, \mathrm{C}_{\infty}$, $\mathrm{HI}$ and eGI are summarized in Table 3. The analysis of the variance amongst the millet substrates, for six samples, revealed that the changes in $\mathrm{C}_{\infty}$, $\mathrm{HI}$ and eGI were significant $(\mathrm{P}<0.05)$ between free extractable proteins or proteins and lipids substrates, like untreated flour and free extractable phenolic compounds or free lipids substrates. However, the changes in $\mathrm{k}$ were non-significant $(\mathrm{P}>0.05)$ as shown in Table 4. Exponential model properties have been used to describe in vitro starch digestion of raw and processed food and feed $[12,16]$. The starch digestion parameters have revealed the inherent susceptibility of starches to amylase hydrolysis [12, 20, 21]. The percentages of starch hydrolysis at infinite time $\left(\mathrm{C}_{\infty}\right)$ ranged from 14.21 to $22.22 \%$ for all flour substrates (MF) and ranged from 53.50 to $83.10 \%$ after extraction of lipids and hydrolysable proteins (MF-P-L). The extent of reactions indicated that these substrates had low susceptibility to digestion. Two substrates after lipid extractions (MLT.Saf and MLT.Ham) and one substrate after phenolic compound extractions (MLH.Z) had medium susceptibility to digestion, $\mathrm{C}_{\infty}$ values ranged from 37.91 to $51.75 \%$. High susceptibility to digestion was registered for all flour substrates after protein hydrolysate or lipids plus protein hydrolysate extractions with 53.50 to $94.38 \% \mathrm{C}_{\infty}$ values. The results demonstrate that in studied pearl millet samples, extraction of protein hydrolysates from flours produced more effective starch substrates for hydrolysis than obtained from flour without treatments or flour after extraction of lipids or phenolic compounds. In contrast, the effect of lipids on the in-vitro starch digestibility of the kodo millet was found to be more significant than that of proteins [22]. When comparing the values of $\mathrm{C}_{\infty}$ in starch digestion, the differences between the substrates can be explained by the change in structure and architecture of grain endosperm and decrease in protein content. The protein hydrolysis processes led to the loss of a part of the endosperm crystallinity, the formation of smaller parts of the protein matrix and to the formation of starch voids in the endosperm. The previous change in the endosperm structure helped the external enzyme diffusion to the surface of the starch granule and the internal enzyme diffusion in the granule pores and channels. Thus, starch digestibility was high after extraction of protein hydrolysates. The flour substrates were composed of endosperm particle regions, which were extremely dense, hard, with high protein content and high resistance to enzymatic degradation [11]. The endosperm protein, associated with the type and location of protein, have been demonstrated to be responsible for many of the differences in starch digestion between slowly digested substrates and those that are rapidly digested [23].

The modeling of starch digestion kinetics is required to derive more quantitative information on digestibility properties. The HI and eGI are reported in Table 3 . The eGI of millet flour substrates ranged from the lowest in MLH.Z (27.41) to the highest in MLH.epc (37.36). The values obtained were less than the values of wheat flour (37.53), rice flour (53.25) [22], Canadian barley (32), Indian wheat (43), Canadian wheat (60) made from whole kernels [24], and nine sorghum flours grown in Algeria (68.70-109.30) [25]. 
After lipid extraction, the eGI value of the millet flour (MF) increased from 29.01 to 57.22 for MLT.saf and from 36.55 to 62.21 for MLT.Ham, while for the remaining samples the range was between 38.78 and 44.97. In the previous work, the interaction between starch and lipid was known to have effects on the enzymatic-hydrolysis rates and physical properties of starches [26]. After extraction of phenolic compounds, there was not much difference of eGI with a range of 31.68-44.34, except for MLH.Z, which increased from 27.41 to 70.23 . These results indicate that phenolic compounds had very little effect on starch digestion. The eGI range increased from 29.01-36.55 for the flours to 83.76-121.44 after extraction of protein hydrolysate and 77.50-119.82 after extraction of lipids plus protein hydrolysates. Previous results have confirmed that endogenous proteins and lipids can inhibit starch digestion in an important staple food with reduced glycemic-index [27, 28]. According to the classification of glycemic index content as previously suggested [29], the results indicate that starches in all the studied pearl millet flours, four lipids free and five free of extractable phenolic compounds can be classified as having a low GI $(<55)$, with values ranging between 31.36 and 44.97. In contrast, all flours free of extractable proteins or lipids plus proteins had the highest glycemic index (>69), with values ranging between 77.50 and 121.44 . These eGI values obtained for pearl millet processed by dry milling and extraction of hydrolysed proteins, are higher than different varieties of processed millet (cooked, porridge, steamed bread, pancake, muffin, extruded snack, couscous and roti) from $49.9 \%$ (Koko, porridge) to $69.4 \%$ (Foxtail, porridge) [27]. The eGI range values of some major cereals like rice, barley and oats in their cooked form were reported to be 60-102, 55-65 and 77-100, respectively $[20,30,31,32]$. The eGI values of pearl millet substrates, prepared in this work, were in the following order: MF-P $>$ MF-L-P $>$ MF-L $>$ MF-PP $>$ MF. Compared with the results of Annor et al. [22], the eGI of kodo millet is in the following order: kodo millet starch (47.81) >MF-L-P (46.76) >MF-L (42.66) >MF-P (36.03) >MF (32.47). According to previous results [28], the eGI of cooked rice samples was in the following order: RF (rice flour) (88.9) $>$ RF-L (91.5) $>$ RF-P (92.3) $>$ RF-L-P (94.5). These results showed that the treatment or processing applied on different grains or same grains but from different regions led to different effects on starch digestion.

Processing methods employed in this work improved the nutritional and starch digestion properties of millet grains. The whole grain flour (MF) had lower expected glycemic index (eGI) than flour substrates after treatments (MF-PP, MF-L, MF-L-P or MF-P) as well as flours or processed grains from major cereals [20, 27, 28, 30, 31, 32]. The presence of protein may be responsible for lower starch digestibility. The extraction of hydrolysed proteins from millet flour was shown to increase in vitro starch digestibility significantly.

Based on these results, processing had an effect on the starch digestion of the whole grain products from the pearl millet samples grown in arid regions of Algeria. Therefore, the whole grain flour and other flours obtained after lipid or phenolic compounds extraction with their hypoglycemic property can be a potential food source for controlling diabetes and obesity. The high glycemic index flour obtained after extraction of protein hydrolysates can be included in the diet. However, these foods should be consumed in association with foods of good nutritional quality that help to reduce post-prandial blood glucose level. However, the intake of flour that causes smaller increase in blood glucose 


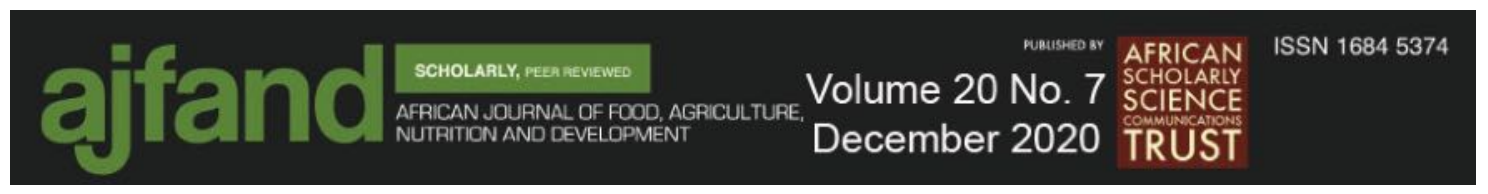

level is often preferred in some situations, for example, during hypoglycemia or for the maintenance of stored glycogen levels in athletes [33].

\section{CONCLUSION}

In this work, the kinetic studies showed that the first-order model could assess the modeling of starch digestion in uncooked pearl millet flours after pretreatments to extract lipids or phenolic compounds or proteins. There were different effects of some nonstarch compounds in pearl millet grains on the in vitro starch digestion and glycemic index.

In general, the extraction of phenolic compounds caused no significant increases in the in vitro starch digestibility, while the extraction of lipids or protein hydrolysates had significant impacts. The effects of proteins on the in vitro starch digestibility of pearl millet were found to be more significant than those of lipids and phenolic compounds. Finally, the results suggest that there are good opportunities for the utilization of pearl millet grains grown in arid Sahara areas of south Algeria (Tidikelt and Hoggar), as nutritional agents with potential health benefits.

\section{ACKNOWLEDGEMENTS}

I would like to thank Mr Kabache Taieb and Mr Daoudi Mourad from the Department of English at ENS Laghouat for their kind help and assistance in revising the paper. 


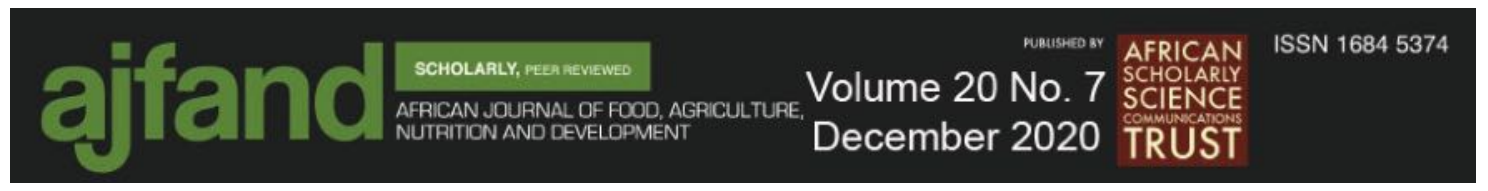

Table 1: Pearl millet (P. glaucum $(L) R B r)$ landraces from arid areas of Algeria: Tidikelt and Hoggar

\begin{tabular}{|l|l|l|l|l|}
\hline No. & Samples codes & Locality & Region & Status \\
\hline 01 & MLT.P.P & FoggaratEzzoua & Tidikelt & Landrace \\
\hline 02 & MLT.Saf & FoggaratEzzoua & Tidikelt & Landrace \\
\hline 03 & MLT.Ham & Djafou & Tidikelt & Landrace \\
\hline 04 & MLH.Z & In Amghel & Hoggar & Landrace \\
\hline 05 & MLH.epc & Tamanrasset & Hoggar & Landrace \\
\hline 06 & MDH.Saf.T & Abalessa & Hoggar & Domesticate \\
\hline
\end{tabular}

Domesticate*: introduced from neighboring country Niger 


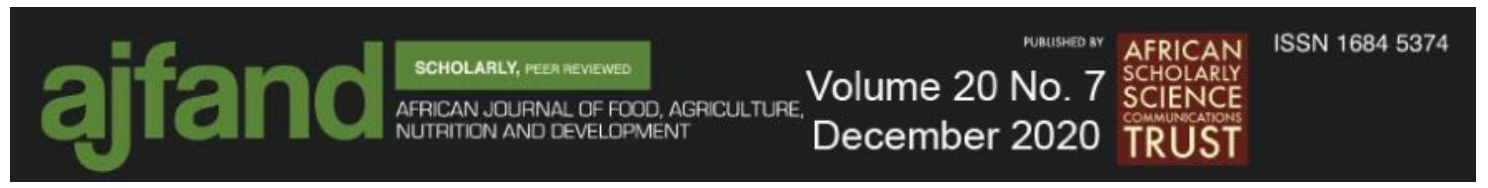

Table 2: Protein, fat and total starch of pearl millet substrates

\begin{tabular}{|c|c|c|c|c|}
\hline $\begin{array}{l}\text { Landraces } \\
\text { codes }\end{array}$ & Samples & $\begin{array}{l}\text { Protein }(\%, \\
\text { dry weight) }\end{array}$ & $\begin{array}{c}\text { Fat }(\%, \text { dry } \\
\text { weight })\end{array}$ & $\begin{array}{c}\text { Total starch }(\%, \\
\text { dry weight })^{\mathrm{a}}\end{array}$ \\
\hline \multirow[t]{2}{*}{ MLT.P.P } & $\mathrm{MF}$ & $15.18 \pm 0.71^{a}$ & 10.18 & $58.82 \pm 5.56$ \\
\hline & MF-P-L & $10.33 \pm 0.94$ & 07.97 & - \\
\hline \multirow[t]{2}{*}{ MLT.Saf } & $\mathrm{MF}$ & $11.41 \pm 0.20^{\mathrm{a}}$ & 08.27 & $65.29 \pm 7.19$ \\
\hline & MF-P-L & $07.64 \pm 0.12$ & 05.91 & - \\
\hline \multirow[t]{2}{*}{ MLT.Ham } & MF & $16.89 \pm 0.76^{\mathrm{a}}$ & 08.43 & $65.81 \pm 2.12$ \\
\hline & MF-P-L & $10.38 \pm 0.36$ & 11.18 & - \\
\hline \multirow[t]{2}{*}{ MLH.Z } & MF & $14.87 \pm 0.50^{a}$ & 09.12 & $69.07 \pm 3.09$ \\
\hline & MF-P-L & $12.64 \pm 1.58$ & 06.55 & - \\
\hline \multirow[t]{2}{*}{ MLH.epc } & $\mathrm{MF}$ & $13.30 \pm 0.89^{a}$ & 11.18 & $63.06 \pm 4.19$ \\
\hline & MF-P-L & $12.00 \pm 0.62$ & 05.10 & - \\
\hline \multirow[t]{2}{*}{ MDH.Saf.T } & $\mathrm{MF}$ & $14.24 \pm 1.55^{\mathrm{a}}$ & 09.44 & $59.53 \pm 9.69$ \\
\hline & MF-P-L & $09.98 \pm 0.60$ & 07.29 & - \\
\hline
\end{tabular}

$\mathbf{M F}=$ Whole grain flour, $\mathbf{M F}-\mathbf{P}-\mathbf{L}=$ Millet flour after extraction of lipids and hydrolysable proteins

apublished values from Lemgharbi et al. [5] 


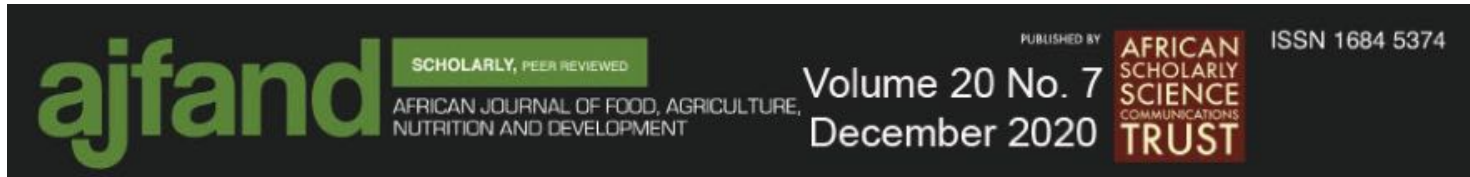

Table 3: Kinetic parameters of first order reaction model, hydrolysis indices and expected glycemic indexes values for starch substrates prepared from pearl millet grains ${ }^{\text {a }}$

\begin{tabular}{|c|c|c|c|c|c|c|c|}
\hline $\begin{array}{l}\text { Landraces } \\
\text { codes }\end{array}$ & Substrates $^{b}$ & $k\left(\min ^{-1}\right)$ & $\begin{array}{l}\text { Std } \\
\text { Error }\end{array}$ & $\mathrm{C}_{\infty}(\%)$ & HI (\%) & eGI & $\mathbf{R}^{2}$ \\
\hline \multirow[t]{5}{*}{ MLT.P.P } & $\mathrm{MF}^{\mathrm{c}}$ & 0.130 & 0.86 & 19.42 & 29.30 & 33.45 & 0.994 \\
\hline & MF-L & 0.200 & 3.06 & 27.61 & 42.65 & 44.97 & 0.977 \\
\hline & MF-P & 0.140 & 2.13 & 75.93 & 114.66 & 107.04 & 0.968 \\
\hline & MF-L-P & 0.180 & 5.26 & 58.26 & 89.57 & 85.41 & 0.924 \\
\hline & MF-PP & 0.064 & 1.02 & 29.90 & 41.93 & 44.34 & 0.954 \\
\hline \multirow[t]{5}{*}{ MLT.Saf } & $\mathrm{MF}^{\mathrm{c}}$ & 0.230 & 1.45 & 15.54 & 24.14 & 29.01 & 0.996 \\
\hline & MF-L & 0.120 & 0.93 & 37.91 & 56.87 & 57.22 & 0.992 \\
\hline & MF-P & 0.180 & 4.54 & 57.02 & 87.66 & 83.76 & 0.947 \\
\hline & MF-L-P & 0.140 & 3.92 & 57.36 & 86.96 & 83.16 & 0.893 \\
\hline & MF-PP & 0.110 & 1.61 & 21.25 & 31.66 & 35.50 & 0.972 \\
\hline \multirow[t]{5}{*}{ MLT.Ham } & $\mathrm{MF}^{\mathrm{c}}$ & 0.210 & 4.50 & 21.25 & 32.90 & 36.55 & 0.958 \\
\hline & MF-L & 0.047 & 0.42 & 47.21 & 62.66 & 62.21 & 0.984 \\
\hline & MF-P & 0.064 & 1.42 & 72.90 & 102.22 & 96.31 & 0.910 \\
\hline & MF-L-P & 0.100 & 2.63 & 54.41 & 80.44 & 77.50 & 0.895 \\
\hline & MF-PP & 0.054 & 0.46 & 25.22 & 34.39 & 37.84 & 0.985 \\
\hline \multirow[t]{5}{*}{ MLH.Z } & $\mathrm{MF}^{\mathrm{c}}$ & 0.290 & 9.22 & 14.21 & 22.29 & 27.41 & 0.910 \\
\hline & MF-L & 0.160 & 2.60 & 25.74 & 39.33 & 42.10 & 0.970 \\
\hline & MF-P & 0.330 & 5.20 & 58.64 & 92.14 & 87.63 & 0.981 \\
\hline & MF-L-P & 0.360 & 8.54 & 53.50 & 84.25 & 80.82 & 0.966 \\
\hline & MF-PP & 0.062 & 0.75 & 51.75 & 71.91 & 70.23 & 0.974 \\
\hline MLH.epc & $\mathrm{MF}^{\mathrm{c}}$ & 0.150 & 0.94 & 22.22 & 33.83 & 37.36 & 0.996 \\
\hline
\end{tabular}




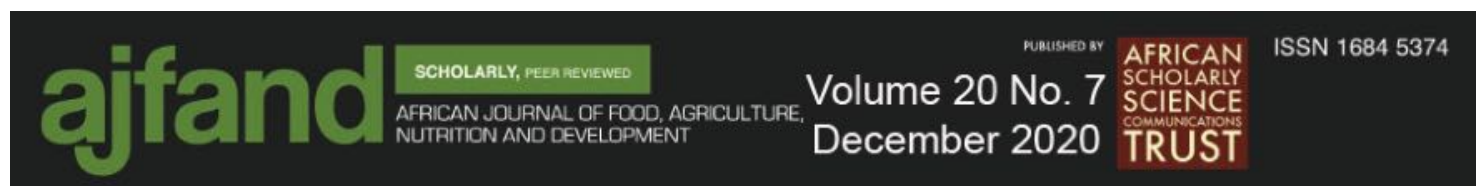

\begin{tabular}{|l|l|l|l|l|l|l|l|}
\hline & MF-L & 0,034 & $\mathbf{0 . 9 6}$ & 26.19 & 32.05 & 35.82 & 0.902 \\
\cline { 2 - 8 } & MF-P & 0.260 & $\mathbf{6 . 4 4}$ & 68.24 & 106.50 & 99.98 & 0.954 \\
\cline { 2 - 8 } & MF-L-P & 0.069 & $\mathbf{1 . 5 4}$ & 68.60 & 97.23 & 92.01 & 0.914 \\
\cline { 2 - 8 } & MF-PP & 0.130 & $\mathbf{1 . 9 1}$ & 17.81 & 26.87 & 31.36 & 0.974 \\
\hline MDH.Saf.T & MF & 0.200 & $\mathbf{6 . 6 4}$ & 18.15 & 28.04 & 32.37 & 0.898 \\
\hline & MF-L & 0.054 & $\mathbf{1 . 0 0}$ & 26.02 & 35.48 & 38.78 & 0.935 \\
\hline & MF-P & 0.061 & $\mathbf{0 . 8 9}$ & 94.38 & 131.37 & 121.44 & 0.959 \\
\hline & MF-L-P & 0.250 & $\mathbf{5 . 8 3}$ & 83.10 & 129.49 & 119.82 & 0.950 \\
\hline & MF-PP & 0.210 & $\mathbf{3 . 5 8}$ & 17.60 & 27.25 & 31.68 & 0.973 \\
\hline
\end{tabular}

a Values are estimated from fit to experimental data, with $\mathrm{R}^{2}>0.9$ and standard Error of estimate (SEE) $<6 \%$ for most landraces. $\mathrm{k}$ is the rate constant $\left(\mathrm{min}^{-1}\right), \mathrm{C}_{\infty}$ is the percentage of starch hydrolyzed at infinite time (recorded after 120 min of digestion), $\mathrm{HI}$ is the hydrolysis index and eGI is expected glycemic index

${ }^{b}$ Substrates: $\mathbf{M F}=$ Whole grain flour; $\mathbf{M F}-\mathbf{L}=$ Flour after extraction of lipids; $\mathbf{M F}-\mathbf{P}=$ Flour after extraction hydrolysable proteins; $\mathbf{M F}-\mathbf{P}-\mathbf{L}=$ Flour after extraction of lipids and hydrolysable proteins; and MF-PP=Flour after extraction of phenolic compounds.

c Published values from Lemgharbi et al. [6] 


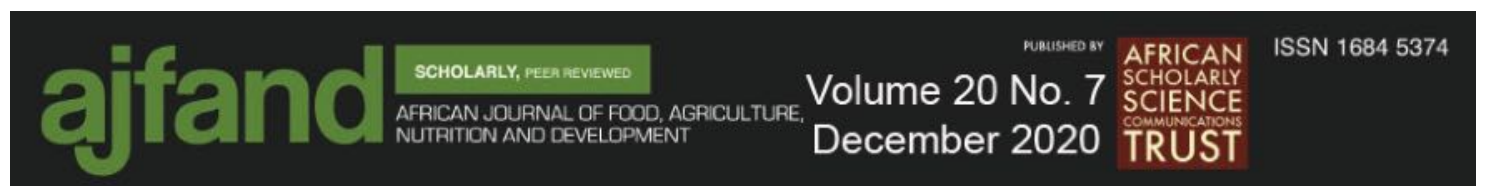

Table 4: Effects of non-starch compounds on digestibility and expected glycemic index (eGI) parameters for pearl millet starch obtaibed from different grain processing treatments

\begin{tabular}{|l|l|l|l|l|}
\hline Treatments & $\mathbf{k}\left(\mathbf{m i n}^{-\mathbf{1}}\right)$ & $\mathbf{C}_{\infty}(\mathbf{\%})$ & HI (\%) & eGI \\
\hline MF & $0.20 \pm 0.06 \mathrm{~b}$ & $18.46 \pm 3.15 \mathrm{a}$ & $18.47 \pm 3.14 *$ & $32.69 \pm 3.97 \mathrm{ab}$ \\
\hline MF-L & $0.10 \pm 0.07 \mathrm{a}$ & $31.78 \pm 8.88 \mathrm{~b}$ & $44.84 \pm 12.24 \mathrm{a}$ & $46.85 \pm 10.55 \mathrm{~b}$ \\
\hline MF-P & $0.17 \pm 0.11 \mathrm{ab}$ & $71.18 \pm 13.64 \mathrm{c}$ & $105.76 \pm 15.88 \mathrm{~b}$ & $99.36 \pm 13.69 \mathrm{c}$ \\
\hline MF-L-P & $0.17 \pm 0.11 \mathrm{ab}$ & $62.54 \pm 11.42 \mathrm{c}$ & $94.66 \pm 17.97 \mathrm{~b}$ & $89.79 \pm 15.50 \mathrm{c}$ \\
\hline MF-PP & $0.10 \pm 0.06 \mathrm{a}$ & $27.25 \pm 12.88 \mathrm{ab}$ & $39.00 \pm 17.04 \mathrm{a}$ & $41.82 \pm 14.71 \mathrm{ab}$ \\
\hline
\end{tabular}

Data presented as mean $\pm \mathrm{SD}(\mathrm{n}=6)$. ANOVA followed by Fisher's least significant difference (LSD) test was performed to search for parameters differences in the samples. In a row, means followed by the same letters (a,b and c) are not significantly different $(p>0.05)$ between treatments. * The mean difference is significant at the 0.05 level. $\mathrm{k}$ the rate constant $\left(\mathrm{min}^{-1}\right), \mathrm{C}_{\infty}$ is the percentage of starch hydrolyzed at infinite time (recorded after 120 min of digestion), and $\mathrm{HI}$ is the hydrolysis index 


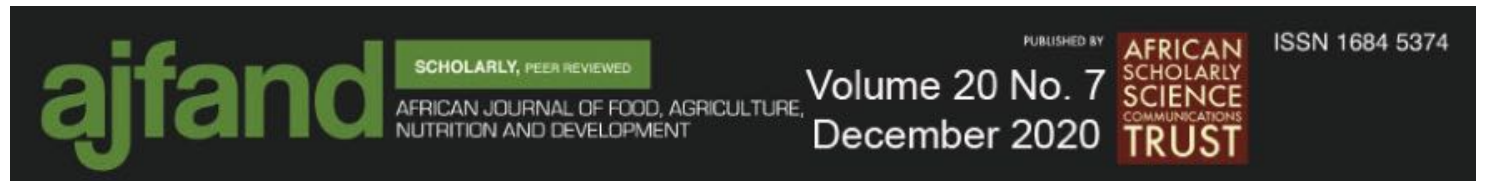

\section{REFERENCES}

1. Devi PB, Vijayabharathi R, Sathyabama S, Malleshi NG and VB Priyadarisini Health benefits of finger millet (Eleusinecoracana L.) polyphenols and dietary fiber: a review. Journal of Food Science and Technology. 2011; 51(6): 1021-1040.

2. Watson R, Singh $\mathbf{R}$ and $\mathbf{T}$ Takahashi The Role of Functional Food Security in Global Health. 2018; $1^{\text {nd }}$ ed. New York, Academic Press.

3. Taylor JRN Millet: Pearl, in Reference Module in Food Science. 2016; 1-9.

4. FAO and ICRISAT. The world sorghum and millet economies: Facts, trends and outlook: FAO and ICRISAT, 1996.

5. Lemgharbi M, Belhadi B, Souilah R, Terbag L, Djabali D and B Nadjemi Biodiversity of Pearl Millet [Pennisetumglaucum (L.) R. Br.] in Southern Algeria (Hoggar Region). American Journal of Plant Sciences. 2016; 7(12): 1673-1684.

6. Lemgharbi M, Souilah R, Belhadi B, Terbag L, Djabali D and B Nadjemi Starch digestion in pearl millet (Pennisetumglaucum $(L$.) R. Br.) flour from arid area of Algeria. Journal of Applied Botany and Food Quality. 2017; 90: $126-131$.

7. Rathore S, Singh K and V Kumar Millet grain processing, utilization and its role in health promotion: A review. International Journal of Nutrition and Food Sciences. 2016; 5(5): 318-329.

8. Saleh ASM, Zhang $\mathbf{Q}$, Chen $\mathbf{J}$ and $\mathbf{Q}$ Shen Millet grains: Nutritional quality, processing, and potential health benefits. Comprehensive Reviews in Food Science and Food Safety. 2013; 12: 281-295.

9. Jenkins DJA, Kendall CWC, Augustin LSA, Franceschi S, Hamidi M, Marchie A, Jenkins AL and $M$ Axelsen Glycemic index: overview of implications in health and disease. American Journal of Clinical Nutrition. (2002); 76(1): 266S-273S.

10. Tamura M, Okazaki Y, Kumagai $\mathbf{C}$ and $\mathbf{Y}$ Ogawa The importance of an oral digestion step in evaluating simulated in vitro digestibility of starch from cooked rice grain. Food Research International. 2017; (94): 6-12.

11. Rooney $\mathbf{L W}$ and RL Pflugfelder Factors affecting starch digestibility with special emphasis on sorghum and corn. Journal of Animal Science. 1986; 63: 1607-1623.

12. Goni I, Garcia-Alonsa A and FA Saura-Calixto starch hydrolysis procedure to estimate glycemic index. Nutrition Research. 1997; 17: 427-437.

13. Khadambi TN Antimicrobial Properties of Phenolic Compounds from Sorghum. Pretoria, South Africa 2007.: University of Pretoria, MSc thesis. 


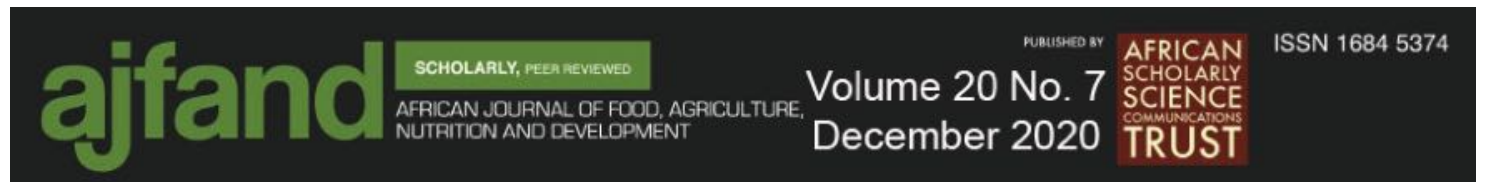

14. AACC. Approved Methods of the AACC 2000.10th ed. AACC International, St. Paul, MN, U. S. A.

15. Shull JM, Oumarou M, Kirleis AW and JW Clark Sorghum Quality Laboratory Manual for Use in West Africa. 1987: Purdue Research Foundation, West Lafayette, Indiana.

16. Ezeogu LI, Duodua KG and JRN Taylor Effects of endosperm texture and cooking conditions on the in vitro starch digestibility of sorghum and maize flours. Journal of Cereal Science. 2005; 42: 33-44.

17. FAO. 1995. Sorghum and millets in human nutrition. collection FAO, Food and Nutrition Series ( ${ }^{\circ} 27$, pp.198) Rome, Italy.

18. Singh RB, Khan S, Chauhan Anil K, Singh M, Jaglan P, Yadav P, Takahashi T and LR Juneja In book: Watson, R., Singh, R., and Takahashi, T. 2018. The Role of Functional Food Security in Global Health. $1^{\text {nd }}$ ed.p.457-468. New York: Academic Press.

19. Abdalla A A, El Tinay AH, Mohamed BE and AH Abdalla Proximate composition, starch, phytate and mineral contents of 10 pearl millet genotypes. Food Chemistry. 1998; 63(2): 243-246.

20. Frei M, Siddhuraju $\mathbf{P}$ and $\mathbf{K}$ Becker Studies on the in vitro starch digestibility and glycemic index of six different indigenous rice cultivars from the Philippines. Food Chemistry. 2003; 83: 395-402.

21. Sopade PA Cereal processing and glycaemic response. International Journal of Food Science and Technology. 2017; 52(1): 22-37.

22. Annor GA, Marcone $\mathbf{M}$, Bertoft $\mathbf{E}$ and $\mathbf{K}$ Seetharaman In vitro starch digestibility and expected glycemic index of kodo millet (paspalumscrobiculatum) as affect by starch-protein-lipid interaction. Cereal Chemistry. 2013; 90(2): 211217.

23. Giuberti G, Gallo A, Masoero F, Ferraretto LF, Hoffman PC and RD Shaver Factors affecting starch utilisation in large animal food production system: A review. Starch/Starke. 2014; 66:72-90.

24. Foster-Powell K, Holt SHA and CJ Brand-Mille International table of glycemic index and glycemic load values. The American Journal of Clinical Nutrition. 2002; 76: $5-56$.

25. Souilah R, Djabali D, Belhadi B, Mokrane H, Boudries $\mathbf{N}$ and B Nadjemi In vitro starch digestion in sorghum flour from Algerian cultivars. Food Science and Nutrition. 2014; 2(3): 251-259. 


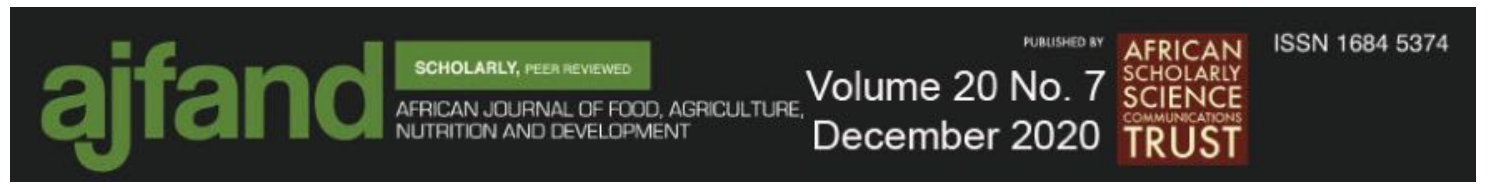

26. Ai Y, Hasjim $\mathbf{J}$ and $\mathbf{J L}$ Jane Effects of lipids on enzymatic hydrolysis and physical properties of starch. Carbohydrate Polymers. 2013; 92(1): 120-127.

27. Annor GA, Tyl C, Marcone M, Ragaee S and A Marti Why do millets have slower starch and protein digestibility than other cereals? Review. Trends in Food Science and Technology. 2017; 66: 73-83.

28. Ye J, Hu X, Luo S, McClements DJ, Liang L and C Liu Effect of endogenous proteins and lipids on starch digestibility in rice flour. Food Research International. 2018; 106: 404-409.

29. Brand-Miller J, Wolever TMS, Foster-Powell $\mathbf{K}$ and $\mathbf{S}$ Colagiuri The new glucose revolution. $2^{\text {th }}$ ed. New York 2003: Marlowe and Company.

30. Granfeldt Y, Bjorck I, Drews A and J Tovar An in vitro procedure based on chewing to predict metabolic response to starch in cereal and legume products. European Journal of Clinical Nutrition. 1992; 46: 649-660.

31. Hu P, Zhao H, Duan Z,Linlin Z and D Wu Starch digestibility and the estimated glycemic score of different types of rice differing in amylose contents. Journal of Cereal Science. 2004; 40(3): 231-237.

32. Kim JC and BI White In vitro digestion rate and estimated glycemic index of oat flour from tropical and high $\beta$-glucan oat lines. Journal of Agricultural and Food Chemistry. 2012; 60(20): 5237-5242.

33. Candido FG, Pereira EV and RG Alfenas Use of the glycemic index in nutrition education. Brazilian Journal of Nutrition. 2013; 26(1):89-96. 